\title{
Use of clomiphene citrate protocol for controlled ovarian stimulation impairs endometrial maturity
}

\author{
Ivan Sereno Montenegro 1,2,3,4,5, Cristiana Palma Kuhl2,3,5, Raquel de Almeida Schneider 2,3,5, Suzana de Azevedo \\ Zachia $^{3}$, Isabel Cirne Lima de Oliveira Durli ${ }^{1,2,3,5}$, Paula Barros Terraciano ${ }^{1,2,3,5}$, Raquel Camara Rivero ${ }^{2,4}$, Eduardo \\ P Passos $1,2,3,5$ \\ ${ }^{1}$ Gynecology and Obstetrics Unit, Hospital de Clínicas de Porto Alegre, Porto Alegre, Brazil \\ 2Gynecology and Obstetrics Department, Universidade Federal do Rio Grande do Sul, Porto Alegre, Brazil \\ ${ }^{3}$ Embryology and Cellular Differentiation Lab, Hospital de Clínicas de Porto Alegre, Porto Alegre, Brazil \\ ${ }^{4}$ Pathology Unit, Hospital de Clínicas de Porto Alegre, Porto Alegre, Brazil \\ ${ }^{5}$ Postgraduate Program in Health Sciences: Gynecology and Obstetrics of Universidade Federal do Rio Grande \\ do Sul
}

This study was presented at the:

XXIII Brazilian Congress on Assisted Reproduction

$58^{\text {th }}$ Brazilian Congress on Gynecology and Obstetrics

\begin{abstract}
Introduction: Despite recent advances in assisted reproduction techniques and recent knowledge regarding embryo and endometrium quality, implantation and birth rates remain low. The objective of this study was to investigate whether clomiphene citrate alters endometrial maturation in infertile patients.
\end{abstract}

Methods: In a prospective self-matched cohort study, we assessed the ovulation of women in spontaneous and stimulated cycles (with clomiphene citrate). We determined the ovulation day by ultrasound scanning. In both cycles, we took four blood samples (BS1 - at early proliferative phase, BS2 - at mid proliferative phase, BS3 - after ovulation and BS4 - at mid luteal phase) to determine the serum concentrations of $\mathrm{FSH}, \mathrm{LH}$, estradiol and progesterone. We retrieved an endometrial biopsy five days after ovulation, followed by blinded analysis and classification according to Noyes criteria, in both cycles.

Results: Twenty-two participants completed the study. There were significant differences in FSH BS3 $(p=0.001)$, in LH BS3 and BS4 $(p<0.001$ and $p=0.049$, respectively), in estradiol BS2, BS3 and BS4 ( $p<0.001, p=0.024$ and $p<0.001$, respectively) and in progesterone BS3 and BS4 $(p=0.028$ and $p<0.001$, respectively). Considering Noyes criteria, there was a one-day delay when comparing the stimulated cycle with the spontaneous cycle $(p=0.004)$, and a two-day delay when comparing the stimulated cycle with the biopsy day.

Conclusion: This study indicates that ovarian stimulation with clomiphene citrate delays the endometrial maturity, and could possibly impair the implantation process due to asynchrony.

Keywords: endometrial receptivity, endometrial maturity, Noyes criteria, assisted reproduction techniques, IVF

\section{INTRODUCTION}

Despite recent advances in assisted reproduction techniques (ART), implantation rates remain low after controlled ovarian stimulation (COS) for in vitro fertilization (IVF), and intracytoplasmic sperm injection (ICSI) treatments (van der Gaast et al., 2008). Embryonic implantation failure remains the major limitation of ART success (Evans et al., 2018; van der Gaast et al., 2008), and although embryo quality is the main determinant of implantation success, maturity and endometrial receptivity are important factors to consider. Embryo implantation followed by gestation depends on a viable and high quality embryo, a receptive endometrium and having a molecular "dialogue" between them (Dieamant et al., 2019). However, what precisely constitutes a receptive endometrium remains uncertain (Bassil et al., 2018; Lessey \& Young, 2019; Li \& Jin, 2013; Paulson, 2019). The implantation process in humans is complex and depends on multiple and successive interactions between the embryo and the endometrium, and it only succeeds when it occurs at a specific time, during the secretory phase of the menstrual cycle, called "implantation window" (Bassil et al., 2018; Enciso et al., 2018; Lessey \& Young, 2019; Li \& Jin, 2013).

Recent research in this area has focused on finding a viable endometrial receptivity marker that may help to identify the best moment to perform an embryo transfer (Edgell et al., 2013; Evans et al., 2018; Kliman \& Frankfurter, 2019; Miravet-Valenciano et al., 2015; Siristatidis et al., 2018). Histologically, endometrial maturity can be classified using the Noyes criteria (Kliman \& Frankfurter, 2019; Noyes et al., 1950; Paulson, 2019), which characterizes the endometrium into its phases (Complementary table).

Clomiphene citrate (CC), commonly used in COS, is a selective estrogen receptor modulator (SERM) that has been the first-line treatment for patients with anovulation or oligomenorrhea for more than 40 years with estrogenic and antiestrogenic effects (Lindheim et al., 2018). It binds to estrogen receptors (ER), leading to the misinterpretation of the estradiol feedback mechanism at a hypothalamic level. The administration of this drug results in increased pituitary gonadotropin release and enhanced follicular development and ovarian response (Lindheim et al., 2018; Palomino et al., 2005).

An important CC issue is its associated low pregnancy rates, notwithstanding high ovulation rates. This phenomenon is partially explained by the antiestrogenic effect on the cervical mucus and the endometrium, causing abnormal endometrial maturation (Jie et al., 2018; Reed et al., 2018). It is therefore, tempting to hypothesize that long-lasting ER occupancy by CC might alter the endometrial cell function, thus affecting the implantation window (Palomino et al., 2005). 
To investigate possible changes caused by $\mathrm{CC}$ in the pattern of endometrial receptivity, we obtained endometrial samples during the midsecretory phase from ovulatory women in a spontaneous cycle and in a CC stimulated cycle.

\section{MATERIALS AND METHODS}

\section{Ethical approval}

The study was developed in accordance with international laws on procedures for dealing with human tissue (including the Declaration of Helsinki for Medical Research involving Human Subjects) and STROBE's publication guidelines (Vandenbroucke et al., 2014). It was submitted and approved by the ethics committee of the Porto Alegre University Hospital (HCPA) and all participants signed an informed consent.

\section{Study population and participants}

In a self-matched prospective cohort, we recruited ovulatory women from Rio Grande do Sul - Brazil, with IVF indication, between the ages of 18 and 35 years, body mass index between 18 and $30 \mathrm{~kg} / \mathrm{m}^{2}$, and with tubal obstruction or male infertility. We excluded those women with anovulation, endometriosis and uterine abnormalities.

\section{Methodology description}

We followed the participants throughout two menstrual cycles. The first one, spontaneous, and the second, stimulated using a daily dose of $100 \mathrm{mg}$ of clomiphene citrate (Clomid $^{\circledR}$, Sanofi, Brazil), for 5 days, initiated on the third day of the cycle. We followed the follicular growth using transvaginal ultrasound, from the second day of the cycle, until sonographic determination of ovulation. During the stimulated cycle, after identifying a follicle with $17 \mathrm{~mm}$ of diameter, the participant received 10.000 UI of chorionic gonadotrophin (Choriomon $\mathrm{M}^{\circledR}$, Meizler UCB Biopharma S.A., Brussels, Belgic), to promote final maturation and ovulation (Figure 1).

In both cycles, collected blood samples from all participants to analyze the serum $\mathrm{FSH}, \mathrm{LH}$, estradiol and progesterone levels: first blood sample (BS1), at initial proliferative phase (days 1-3 of the cycle); second blood sample (BS2), at the mid proliferative phase (days 8-10 of the cycle); third blood sample (BS3), after determination of ovulation by ultrasound; fourth blood sample (BS4), five days after determining ovulation by ultrasound. All hormone assays were performed using electrochemiluminescent immunoassay in the Roche Cobas e602analyzer, according to correspondent kits for FSH, $\mathrm{LH}$, estradiol and progesterone (FSH Elecsys and cobas e analyzers, Roche Diagnostics, USA; LH Elecsys and cobas e analyzers, Roche Diagnostics, USA; Estradiol II Elecsys and cobas e analyzers, Roche Diagnostics, USA; ProgesteroneIII Elecsys and cobas e analyzers, Roche Diagnostics, USA).

We submitted the participants to an endometrial biopsy five days after establishing the ovulation, in both cycles, with a Pipelle curette (Pipelle ${ }^{\circledR}$ de Cornier for endometrial biopsy, Laboratoire C.C.D., France). We fixed the biopsy samples in $10 \%$ buffered neutral formalin, and sent them to HCPA's pathology lab. The specimens were dehydrated with increasing concentration of ethanol before being embedded in paraffin. A portion of endometrial tissue was routinely cut, assembled and stained with hematoxylin for histological dating following the Noyes criteria (Complementary table) (Noyes et al., 1950). The same blinded examiner (RCR), an expert in gynecological pathology at HCPA, evaluated all slides and the result was expressed in whole numbers, using as a reference, a standard menstrual cycle of 28 days of duration and ovulation occurring on the $14^{\text {th }}$ day of the cycle.

\section{Statistical analyses}

FSH, LH, estradiol and progesterone samples were compared using a Generalized Estimating Equation (GEE) model concerning values between collections, cycles and interaction (collection $x$ cycle). We presented the data as mean \pm standard error. For the calculation model, we established the following parameters: unstructured working correlation matrix, robust estimator covariance matrix, and normal distributions with identity function. When significant, we used the Bonferroni post-hoc test to ascertain which blood samples were different. We analyzed the histopathological results of Noyes criteria using the Wilcoxon test for related samples, which compares the distribution of the histopathological data of the endometrial matched samples. We expressed this data using median values (2575). For all tests, a $p<0.05$ was significant.

\section{RESULTS}

\section{Demographic data}

We recruited thirty-six patients and, of these, $22 \mathrm{com}$ pleted the two assessment cycles and were included for analysis of the data collected, description (presented in the Table 1 and Figure 2) and statistical evaluation.

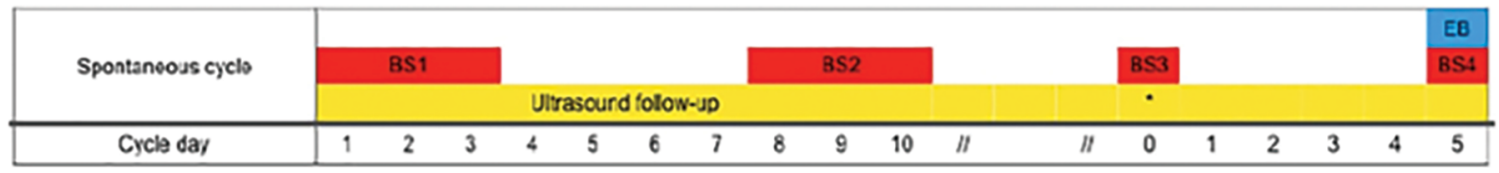

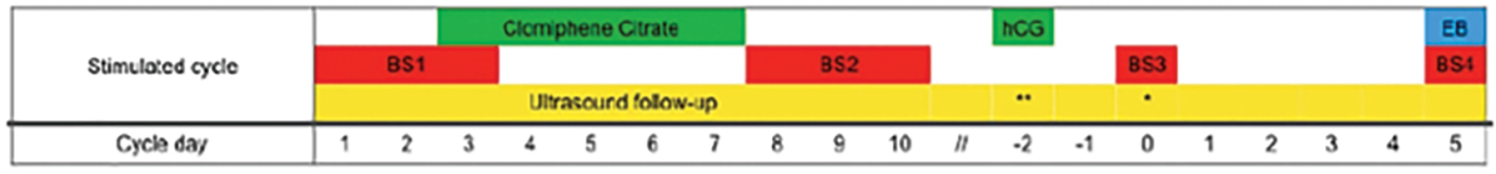

Figure 1. Schematic representation of the assessments in spontaneous and stimulated cycles. Following a spontaneous cycle, all 22 participants underwent a stimulated cycle using $100 \mathrm{mg} /$ day of clomiphene citrate between days 3 and 7 of the cycle. When the leading follicle had a diameter of $17 \mathrm{~mm}$ (represented by $* *$ ), they received 10.000 UI of human chorionic gonadotrophin (hCG) for final oocyte maturation. Endometrial biopsy (EB) was performed 5 days after ovulation confirmation (represented by *) by ultrasonography. In both cycles blood samples (BS) were taken at the early proliferative phase (days $1-3$ ), in the midproliferative phase (days 8-10), when confirmed ovulation, and five days after ovulation. 


\begin{tabular}{|l|c|}
\hline Table 1. Participant demographic data $(\mathrm{n}=22)$ \\
\hline Data & Mean 土 SD \\
\hline Age (years) & $31.5 \pm 3.5$ \\
\hline Weight $(\mathrm{Kg})$ & $64.5 \pm 6.93$ \\
\hline Height $(\mathrm{m})$ & $1.62 \pm 0.06$ \\
\hline Body mass index $\left(\mathrm{Kg} / \mathrm{m}^{2}\right)$ & $24.53 \pm 3.02$ \\
\hline
\end{tabular}

SD - Standard derivation

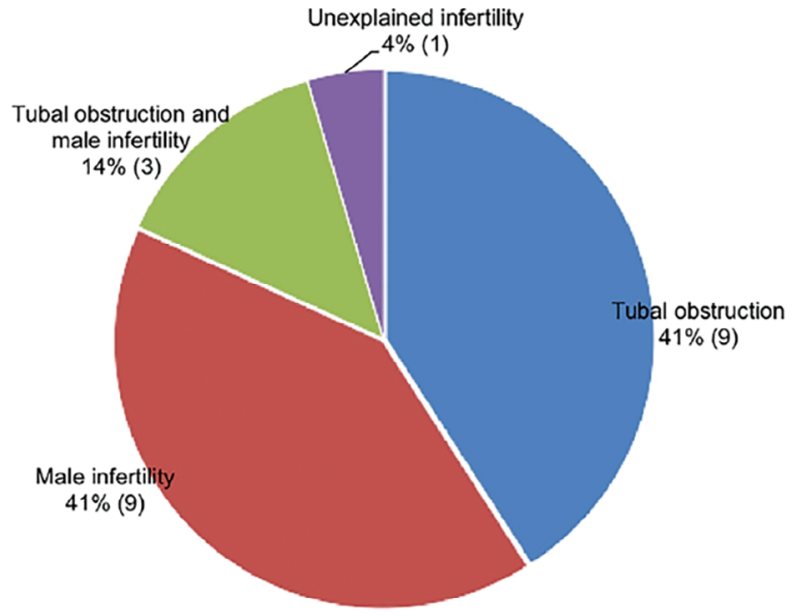

Figure 2. Participants' causes of infertility.

\section{Hormonal analysis}

Table 2 shows the mean serum levels of the hormones $\mathrm{FSH}, \mathrm{LH}$, estradiol and progesterone. When comparing mean values between the corresponding samples for each cycle, there were differences in the FSH dosage comparisons from $\operatorname{BS} 3(p=0.001)$; in LH, from BS3 $(p<0.001)$ and BS4 $(p=0.049)$; in estradiol from BS2 $(p<0.001), \mathrm{BS} 3$ $(p=0.024)$ and BS4 $(p<0.001)$; and in progesterone, from BS3 $(p=0.028)$ and BS4 $(p<0.001)$.

\section{Endometrial analysis}

We evaluated eighteen endometrial matched samples by Noyes criteria tissue analysis (Figure 3 ). Four pairs of samples were withdrawn due to results that showed, at least in one slide, a stromal-glandular dissociation (2 slides), a basal endometrium (1 slide) or could not be evaluated ( 1 slide). The comparison between the median results of the endometrial biopsy from both cycles expressed a difference $(p<0.004)$ of one day (Figure 4$)$.

\section{DISCUSSION}

This study found a one-day delay in the CC stimulated cycle, when analyzing the endometrium following the Noyes criteria. This data supports the idea of asynchrony between the endometrium in the spontaneous and stimulated cycles. Concerning the day of blastocyst transfer, in other words, 5 days after ovulation, there was a 2-day delay which could explain even lower implantation rates when performing a transfer on this day in cycles using CC. It was the first to study that analyzed endometrium matched samples in spontaneous and stimulated cycles from the same infertile women.

Some investigators report on the lack of correlation between the cycle day and endometrial dating by Noyes criteria. Murray et al. (2004) concluded that histologic endometrial dating does not have the accuracy or the precision necessary to provide a valid method for the diagnosis of luteal phase deficiency and, Coutifaris et al. (2004) stated that the endometrial biopsy followed by histological dating provides no useful clinical information as a screening test for infertility. Garrido-Gómez et al. (2013) said that biochemical markers are ideal as alternatives to classic Noyes criteria and suggest that the definition of a genomic signature of human endometrial receptivity can be used as a strategy to overcome subjectivity problems caused by the inter and intracycle variations in Noyes endometrial receptivity dating. In 2018, Bassil et al. found no agreement between the endometrial receptivity array (ERA) and the Noyes histological criteria (Bassil et al., 2018). Despite these relevant findings, they used different methods to reach this conclusion (none of them using the same participant in a spontaneous and in a stimulated cycle) and there are no other validated markers or clinically useful endometrial evaluation methods.

It should be noted that our participants are diagnosed with infertility and with indication of IVF; however, the ones with anovulation, uterine abnormalities and endometriosis were carefully excluded to minimize possible selection biases, as it is considered that these pathologies may modify the endometrial decidualization process. Yet, we biopsied all the participants in the spontaneous cycle and in a CC-stimulated cycle, minimizing other types of selection biases.

The significant increases in $\mathrm{FSH}, \mathrm{LH}$, estradiol and progesterone dosage confirm that participants correctly used the medication provided. As known, CC works by competitive binding to estrogen receptors in the hypothalamus and pituitary, reducing estrogen signaling via receptors and interfering with the feedback mechanism of endogenous estrogen, resulting in an increase in FSH and $\mathrm{LH}$ secretions to stimulate ovarian follicular production, and a consequent increase in estradiol and progesterone (Gadalla et al., 2018). One of our hypotheses is that the supraphysiological increase in the estradiol, progesterone, $\mathrm{FSH}$ and LH levels in stimulated cycles with clomiphene citrate, may be one of the factors responsible for the asynchrony of endometrial histology.

Considering the 22 matched samples of endometrial biopsies, we excluded four pairs from the statistical calculation, two histological results demonstrated a stromal-glandular dissociation and another one a basal endometrium. These findings confirm that CC use for COS causes asynchrony and delayed endometrial development, although it was not used for analysis.

Bonhoff et al. (1996) described the same asynchrony effect in patients undergoing COS with CC for artificial insemination, comparing them with fertile controls. Gonzalez et al. (2001) also reported an endometrial asynchrony and integrins alteration in CC. stimulated cycles and intrauterine device users, when compared to fertile controls.

Looking at these results, we hypothesize that the antiestrogenic effects of CC on the endometrium impairs endometrial proliferation in the proliferative phase of the cycle, which reflects a delayed endometrial maturation in the luteal phase. This finding is confirmed by several studies which concluded that ovulation induction with CC might result in lower endometrial thickness (Gadalla et al., 2018; Reed et al., 2018) and, despite the high rate of ovulation, pregnancy rates are low when using CC (Jie et al., 2018).

There are few limitations to our study. We did not compare these findings to implantation, pregnancy and birth rates, as we consider these outcomes the best predictors for any developed endometrial receptivity test. Despite the small sample of this study, our results show a significant difference in endometrial maturity comparing the 


\begin{tabular}{|c|c|c|c|c|c|c|c|}
\hline \multirow{2}{*}{\multicolumn{2}{|c|}{ Hormone }} & $\begin{array}{c}\text { Spontaneous } \\
\text { Cycle }\end{array}$ & $\begin{array}{c}\text { Stimulated } \\
\text { Cycle }\end{array}$ & Total & \multirow[t]{2}{*}{ p Cycle } & \multirow[t]{2}{*}{ p Sample } & \multirow[t]{2}{*}{$p$ Interaction } \\
\hline & & Mean (SE) & Mean (SE) & Mean (SE) & & & \\
\hline \multirow[t]{5}{*}{ FSH } & Sample 1 & $7.62(0.51)$ & $7.02(0.41)$ & $7.32(0.41)$ & \multirow[t]{5}{*}{0.023} & \multirow[t]{5}{*}{$<0.001$} & \multirow[t]{5}{*}{0.002} \\
\hline & Sample 2 & $6.21(0.56)$ & $6.69(0.74)$ & $6.45(0.62)$ & & & \\
\hline & Sample 3 & $6.83 a(0.62)$ & 9.75b (0.82) & $8.29(0.58)$ & & & \\
\hline & Sample 4 & $3.64(0.22)$ & $3.90(0.36)$ & $3.77(0.21)$ & & & \\
\hline & Total & $6.08(0.30)$ & $6.84(0.42)$ & & & & \\
\hline \multirow[t]{5}{*}{ LH } & Sample 1 & $6.26(0.66)$ & $6.27(0.59)$ & $6.26(0.60)$ & \multirow[t]{5}{*}{$<0.001$} & \multirow[t]{5}{*}{$<0.001$} & \multirow[t]{5}{*}{0.002} \\
\hline & Sample 2 & $8.85(0.96)$ & $9.97(0.84)$ & $9.41(0.80)$ & & & \\
\hline & Sample 3 & 12.50a (1.99) & $22.26 b(2.50)$ & $17.38(1.89)$ & & & \\
\hline & Sample 4 & $6.68 a(0.65)$ & $8.33 b(1.06)$ & $7.50(0.77)$ & & & \\
\hline & Total & $8.57(0.79)$ & $11.71(0.92)$ & & & & \\
\hline \multirow[t]{5}{*}{ Estradiol } & Sample 1 & $40.10(5.31)$ & $38.90(2.37)$ & $39.50(3.39)$ & \multirow[t]{5}{*}{$<0.001$} & \multirow[t]{5}{*}{$<0.001$} & \multirow[t]{5}{*}{$<0.001$} \\
\hline & Sample 2 & $127.08 a(14.17)$ & $480.87 b(54.13)$ & $303.97(29.56)$ & & & \\
\hline & Sample 3 & $111.43 a(13.05)$ & $163.97 b(16.31)$ & $137.70(9.15)$ & & & \\
\hline & Sample 4 & $155.03 a(14.76)$ & $481.22 b(41.30)$ & $318.13(21.81)$ & & & \\
\hline & Total & $108.41(6.65)$ & $291.24(23.25)$ & & & & \\
\hline \multirow[t]{5}{*}{ Progesterone } & Sample 1 & $0.65(0.19)$ & $0.49(0.12)$ & $0.57(0.12)$ & \multirow[t]{5}{*}{0.002} & \multirow[t]{5}{*}{$<0.001$} & \multirow[t]{5}{*}{$<0.001$} \\
\hline & Sample 2 & $0.44(0.07)$ & $0.35(0.06)$ & $0.39(0.05)$ & & & \\
\hline & Sample 3 & $4.87 a(0.79)$ & $2.99 b(0.43)$ & $3.93(0.47)$ & & & \\
\hline & Sample 4 & $13.37 a(0.78)$ & $25.86 b(2.75)$ & $19.62(1.42)$ & & & \\
\hline & Total & $4.83(0.32)$ & $7.42(0.76)$ & & & & \\
\hline
\end{tabular}

SE -Standard Error

Distinct letters represent statistically different means

+ Generalized Estimating Equation Model (GEE)

spontaneous and stimulated cycle with CC. Regardless of the Noyes criteria limits, there are no other validated test to assess endometrial maturity, so that we use the same test, performed by the same blinded observer, in samples of the same participant in order to minimize this bias.

In conclusion, our study found statistically significant changes in the endometrial compartment in patients who used clomiphene citrate for ovarian stimulation, represented by an asynchrony demonstrated by a one-day delay in histological endometrial maturity when comparing spontaneous and stimulated cycles; and a two-days delay when compared the stimulated cycle with the probable day of blastocyst transfer. The freeze-all strategy is a possible approach to be adopted in IVF cycles, to avoid this asynchrony with subsequent transfer in a spontaneous cycle or associated with endometrial preparation. In order to confirm this finding, we need larger prospective studies.

\section{ACKNOWLEDGEMENTS}

We acknowledge the Fundo de Incentivo à Pesquisa e Eventos (FIPE) of Hospital de Clínicas de Porto Alegre for funding this research. We would like to thank the staff from the Gynecology and Obstetrics Unit, Embryology and Cellular Differentiation Lab and Pathology Unit of Hospital de
Clínicas de Porto Alegre and staff of Gynecology and Obstetrics Department of Universidade Federal do Rio Grande do Sul involved in this research.

\section{FUNDING}

This research was supported by Fundo de Incentivo à Pesquisa e Eventos (FIPE) of Hospital de Clínicas de Porto Alegre (number 2017-0180).

\section{CONFLICT OF INTEREST}

All authors have completed the ICMJE uniform disclosure and declare that there was no support from any organization for the submitted paper, no financial relationships with any organizations that might have an interest in the submitted study in the previous 3 years and no other relationships or activities that could appear to have influenced the submitted study.

\section{Corresponding Author:}

Ivan Sereno Montenegro

Department of Obstetrics and Gynecology

Porto Alegre Clinical Hospital

Federal University of Rio Grande do Sul

Porto Alegre - RS - Brazil.

E-mail: ivan.montenegro@yahoo.com.br 


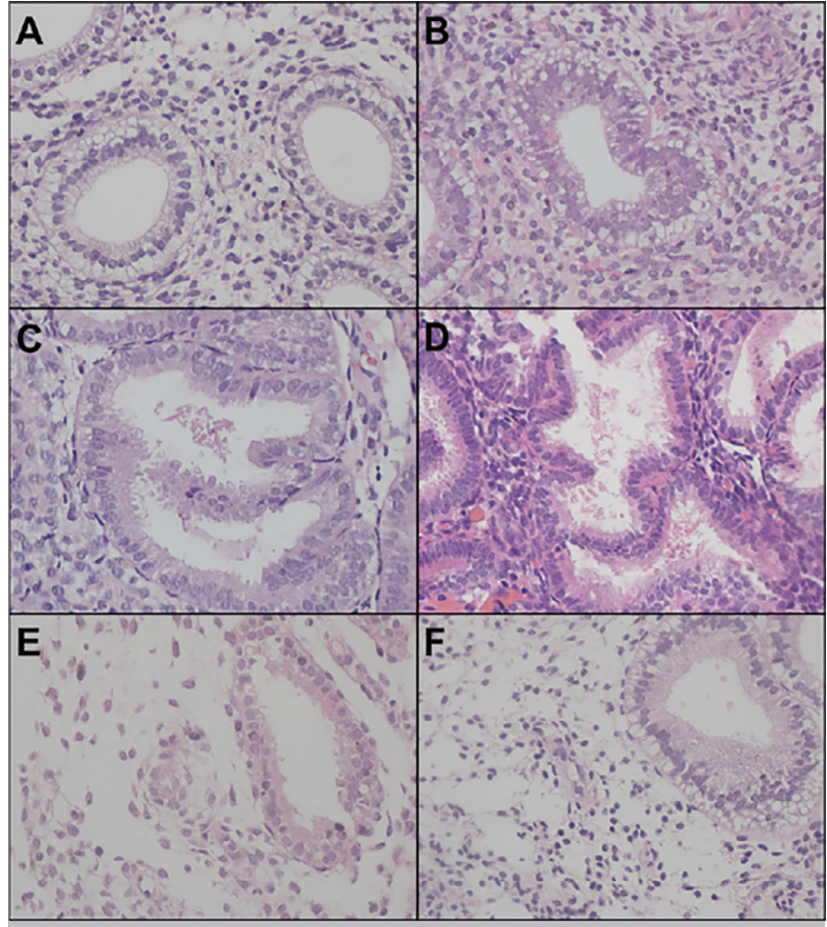

Figure 3. Endometrial cycle dating based on Noyes et al. (1950) criteria (200x): (A) Day 17: "piano key" appearance of glandular epithelium with vacuoles at nuclei level; (B) Day 18: luminal vacuoles with smaller size and the nuclei approaching the base of the glandular cell; (C) Day 19: presence of intraluminal secretion with few vacuoles on cellular cytoplasm, absence of mitosis and pseudo stratification; (D) Day 20: the peak of intraluminal secretion with stromal edema onset, presence of rare vacuoles and round nuclei located at the base of the glandular cell.; (E) Day 23: presence of prominent spiral arterioles with thickened walls, coiling and endothelial proliferation; (F) stromal-glandular dissociation - gland on day 17 with decidualized stroma.

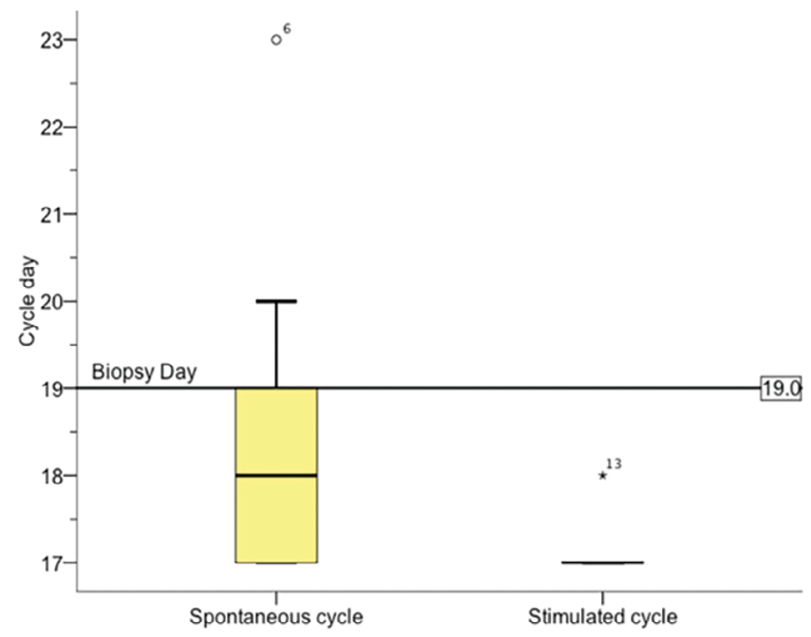

Figure 4. Median comparison of Noyes criteria results.

\section{REFERENCES}

Bassil R, Casper R, Samara N, Hsieh TB, Barzilay E, Orvieto $R$, Haas $J$. Does the endometrial receptivity array really provide personalized embryo transfer? J Assist Reprod Genet. 2018;35:1301-5. PMID: 29737471 DOI: 10.1007/ s10815-018-1190-9

Bonhoff AJ, Naether OG, Johannisson E. Effects of clomiphene citrate stimulation on endometrial structure in infertile women. Hum Reprod. 1996;11:844-9. PMID: 8671338 DOI: $10.1093 / o x f o r d j o u r n a l s . h u m r e p . a 019264$

Coutifaris C, Myers ER, Guzick DS, Diamond MP, Carson SA, Legro RS, McGovern PG, Schlaff WD, Carr BR, Steinkampf MP, Silva S, Vogel DL, Leppert PC ; NICHD National Cooperative Reproductive Medicine Network. Histological dating of timed endometrial biopsy tissue is not related to fertility status. Fertil Steril. 2004;82:1264-72. PMID: 31623723 DOI: 10.1016/j.fertnstert.2004.03.069

Dieamant $F$, Vagnini LD, Petersen CG, Mauri AL, Renzi A, Petersen B, Mattila MC, Nicoletti A, Oliveira JBA, Baruffi R, Franco JG Jr. New therapeutic protocol for improvement of endometrial receptivity (PRIMER) for patients with recurrent implantation failure (RIF) - A pilot study. JBRA Assist Reprod. 2019;23:250-4. PMID: 31091064 DOI: 10.5935/1518-0557.20190035

Edgell TA, Rombauts LJ, Salamonsen LA. Assessing receptivity in the endometrium: the need for a rapid, non-invasive test. Reprod Biomed Online. 2013;27:486-96. PMID: 23933033 DOI: 10.1016/j.rbmo.2013.05.014

Enciso M, Carrascosa JP, Sarasa J, Martínez-Ortiz PA, Munné S, Horcajadas JA, Aizpurua J. Development of a new comprehensive and reliable endometrial receptivity map (ER Map/ER Grade) based on RT-qPCR gene expression analysis. Hum Reprod. 2018;33:220-8. PMID: 29315421 DOI: $10.1093 /$ humrep/dex370

Evans GE, Phillipson GTM, Sykes PH, McNoe LA, Print CG, Evans $\mathrm{JJ}$. Does the endometrial gene expression of fertile women vary within and between cycles? Hum Reprod. 2018;33:452-63. PMID: 29370409 DOI: 10.1093/humrep/dex385

Gadalla MA, Huang S, Wang R, Norman RJ, Abdullah SA, El Saman AM, Ismail AM, van Wely M, Mol BWJ. Effect of clomiphene citrate on endometrial thickness, ovulation, pregnancy and live birth in anovulatory women: systematic review and meta-analysis. Ultrasound Obstet Gynecol. 2018;51:64-76. PMID: 29055102 DOI: 10.1002/uog.18933

Garrido-Gómez T, Ruiz-Alonso M, Blesa D, Diaz-Gimeno $P$, Vilella $F$, Simón $C$. Profiling the gene signature of endometrial receptivity: clinical results. Fertil Steril. 2013;99:1078-85. PMID: 23312228 DOI: 10.1016/j.fertnstert.2012.12.005

Gonzalez RR, Palomino A, Vantman D, Gabler F, Devoto L. Abnormal pattern of integrin expression at the implantation window in endometrium from fertile women treated with clomiphene citrate and users of intrauterine device. Early Pregnancy. 2001;5:132-43. PMID: 11753526 
Jie L, Li D, Yang C, Haiying Z. Tamoxifen versus clomiphene citrate for ovulation induction in infertile women. Eur J Obstet Gynecol Reprod Biol. 2018;228:57-64. PMID: 29909264 DOI: 10.1016/j.ejogrb.2018.06.022

Kliman HJ, Frankfurter D. Clinical approach to recurrent implantation failure: evidence-based evaluation of the endometrium. Fertil Steril. 2019;111:618-28. PMID: 30929719 DOI: $10.1016 /$ j.fertnstert.2019.02.011

Lessey BA, Young SL. What exactly is endometrial receptivity? Fertil Steril. 2019;111:611-7. PMID: 30929718 DOI: $10.1016 /$ j.fertnstert.2019.02.009

Li MQ, Jin LP. Ovarian stimulation for in vitro fertilization alters the protein profile expression in endometrial secretion. Int J Clin Exp Pathol. 2013;6:1964-71. PMID: 24133574

Lindheim SR, Glenn TL, Smith MC, Gagneux P. Ovulation Induction for the General Gynecologist. J Obstet Gynaecol India. 2018;68:242-52. PMID: 30065537 DOI: 10.1007/ s13224-018-1130-8

Miravet-Valenciano JA, Rincon-Bertolin A, Vilella F, Simon C. Understanding and improving endometrial receptivity. Curr Opin Obstet Gynecol. 2015;27:187-92. PMID: 25827647 DOI: $10.1097 / G C 0.0000000000000173$

Murray MJ, Meyer WR, Zaino RJ, Lessey BA, Novotny $D B$, Ireland $K$, Zeng $D$, Fritz MA. A critical analysis of the accuracy, reproducibility, and clinical utility of histologic endometrial dating in fertile women. Fertil Steril. 2004;81:1333-43. PMID: 15136099 DOI: $10.1016 / j . f e r t n-$ stert.2003.11.030
Noyes RW, Hertig AT, Rock J. Dating the endometrial biopsy. Obstet Gynecol Surv. 1950;5:561-4.

Palomino WA, Fuentes A, González RR, Gabler F, Boric MA, Vega $M$, Devoto L. Differential expression of endometrial integrins and progesterone receptor during the window of implantation in normo-ovulatory women treated with clomiphene citrate. Fertil Steril. 2005;83:587-93. PMID: 15749485 DOI: $10.1016 /$ j.fertnstert.2004.11.020

Paulson RJ. Introduction: Endometrial receptivity: evaluation, induction and inhibition. Fertil Steril. 2019;111:609-10. PMID: 30929717 DOI: 10.1016/j.fertnstert.2019.02.029

Reed BG, Wu JL, Nemer LB, Carr BR, Bukulmez O. Use of Clomiphene Citrate in minimal stimulation in vitro fertilization negatively impacts endometrial thickness: an argument for a freeze-all approach. JBRA Assist Reprod. 2018;22:355-62. PMID: 30264948 DOI: 10.5935/1518-0557.20180070

Siristatidis CS, Sertedaki E, Vaidakis D, Varounis C, Trivella M. Metabolomics for improving pregnancy outcomes in women undergoing assisted reproductive technologies. Cochrane Database Syst Rev. 2018;3:CD011872. PMID: 28534597 DOI: 10.1002/14651858.CD011872.pub2

van der Gaast MH, Classen-Linke I, Krusche CA, Beier-Hellwig $\mathrm{K}$, Fauser BC, Beier HM, Macklon NS. Impact of ovarian stimulation on mid-luteal endometrial tissue and secretion markers of receptivity. Reprod Biomed Online. 2008;17:553-63. PMID: 18854111 DOI: $10.1016 /$ S1472-6483(10)60244-1

Vandenbroucke JP, von Elm E, Altman DG, Gøtzsche PC, Mulrow CD, Pocock SJ, Poole C, Schlesselman JJ, Egger M, STROBE initiative. Strengthening the Reporting of Observational Studies in Epidemiology (STROBE): explanation and elaboration. Int J Surg. 2014;12:1500-24. PMID: 25046751 DOI: $10.1016 /$ j.ijsu.2014.07.014 


\begin{tabular}{|c|c|}
\hline \multicolumn{2}{|l|}{ Complementary table. Noyes criteria } \\
\hline Endometrium phase or days & Histopathological characteristics of the endometrium \\
\hline Proliferative phase & $\begin{array}{l}\text { Length varies from } 10-20 \text { days, "ideal" is } 14 \text { days } \\
\text { During this phase, glands become more tortuous due to epithelial proliferation, in } \\
\text { response to estrogen production and estrogen receptors on epithelium }\end{array}$ \\
\hline Early proliferative (days $4-7$ ) & $\begin{array}{l}\text { Thin surface epithelium, straight short glands, compact stroma, minimal mitotic } \\
\text { activity and large nuclei }\end{array}$ \\
\hline Mid proliferative (days $8-10$ ) & $\begin{array}{l}\text { Columnar surface epithelium; longer curving glands, variable stromal edema } \\
\text { and numerous mitotic figures }\end{array}$ \\
\hline Late proliferative (days $11-14$ ) & $\begin{array}{l}\text { Undulant surface epithelium, tortuous glands with prominent mitotic activity } \\
\text { and pseudostratification; dense stroma, subnuclear vacuoles in less than } 50 \% \\
\text { of glands }\end{array}$ \\
\hline Ovulation & $\begin{array}{l}\text { presence of subnuclear vacuoles in } 50 \% \text { of glands is evidence of ovulation; must } \\
\text { biopsy the functional layer, not the basal layer; to rule out anovulatory cycles, } \\
\text { should biopsy } 2 \text { days before menstruation }\end{array}$ \\
\hline Secretory / luteal phase & $\begin{array}{l}\text { Traditionally assumed to be } 14 \text { days, but may vary } \\
\text { Progesterone secretion inhibits endometrial proliferative activity and induces } \\
\text { secretory activity } \\
\text { Note: secretory material in glands is NOT specific for secretory epithelium; seen } \\
\text { also in disordered proliferative and hyperplastic endometrium and carcinoma } \\
\text { Clinically, secretory endometrium is lush and polypoid with no necrosis; may be } \\
\text { hemorrhagic if close to day } 28\end{array}$ \\
\hline Day 15 & $\begin{array}{l}\text { No changes from late proliferative; also known as interval endometrium; presence } \\
\text { of scattered nuclear vacuoles is not specific for ovulation (must be } 50 \% \text { or more) }\end{array}$ \\
\hline Day 16 & "Piano key" appearance; subnuclear vacuoles \\
\hline Day 17 & "Piano key" appearance; vacuoles at level of nuclei \\
\hline Day 18 & Luminal vacuoles, smaller size and nuclei approach base of cell \\
\hline Day 19 & Intraluminal secretion begins \\
\hline Days $20-21$ & Maximal secretion \\
\hline Day 22 & Maximal stromal edema in luteal phase; best time for implantation \\
\hline Day 23 & Prominent spiral arterioles (thickened walls, coiling and endothelial proliferation) \\
\hline Day 24 & $\begin{array}{l}\text { Perivascular predecidualization (stromal cell hypertrophy with accumulation of } \\
\text { cytoplasmic eosinophilia); serrated / tortuous glands }\end{array}$ \\
\hline Day 25 & Predecidualization below surface endometrium \\
\hline Day 26 & $\begin{array}{l}\text { Confluence of predecidual tissue; stromal granulocytes (probably lymphocytes) } \\
\text { appear }\end{array}$ \\
\hline Day 27 & Prominent stromal granulocytes; focal necrosis and hemorrhage \\
\hline Day 28 & $\begin{array}{l}\text { Shedding, also called glandular and stromal breakdown; prominent necrosis and } \\
\text { hemorrhage; predecidual stroma and glandular exhaustion; nuclear dust at base } \\
\text { of glandular epithelium; condensed stroma with overlying papillary-syncytial } \\
\text { change; intravascular fibrin thrombi; stromal granulocytes }\end{array}$ \\
\hline
\end{tabular}

Ref: Noyes et al., 1950 